Original Article

\title{
Antifungal efficacy of herbs
}

\author{
Fahad M. Samadi ${ }^{a}$, , Shaista Suhail ${ }^{\mathrm{a}}$, Manjari Sonam ${ }^{\mathrm{a}}$, Neeta Sharma ${ }^{\mathrm{b}}$, Shruti Singh ${ }^{\mathrm{a}}$, \\ Sushil Gupta ${ }^{c}$, Ashwini Dobhal ${ }^{\mathrm{d}}$, Harsha Pradhan ${ }^{\mathrm{e}}$

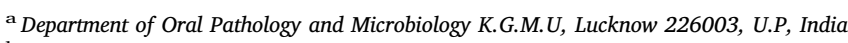 \\ b Department of Botany, Lucknow University, Lucknow 226007, U.P, India \\ ${ }^{\mathrm{c}}$ Department of Oral and Maxillofacial Surgery, Kanpur, India \\ d Department of Oral and Maxillofacial Surgery, Dehradoon, India \\ ${ }^{\mathrm{e}}$ Department of Oral and Maxillofacial Surgery, Career Dental College, Lucknow, India
}

\section{A R T I C L E I N F O}

\section{Keywords:}

OSCC

Candida albicans

Novel Herbs

Antifungal Activity

\begin{abstract}
A B S T R A C T
Candida carriage was reported to be common in oral cancer patients, with C. albicans being the predominant species. The prevalence of diseases caused by Candida species have been found to increase in recent years. Aim: The aim of our study was to find the antifungal activities at MIC of selected fifteen plant leaves extracts prepared in three different solutions (methanol and ethanol) against the opportunistic pathogen Candida albicans isolated from oral cavity infections. It may also help the clinician to treat the patient not only for the particular lesion that is present, but also to treat the infection by Candida albicans so as to reduce its potential to malignant transformation. Material $\mathrm{n}$ methods: Leaves extract of selected plant prepared in methanolic and eethanolic solution have been chosen for the investigation of in vitro antifungal activity which acts as expectorant and not having toxic properties on humans while for comparison or control, antifungal drugs have been taken. Results showed that Candida albicans shows most sensitivity towards the standard antibiotic cotrimoazol but very less towards other drugs like Fluconazole, minocycline, erythromycin respectively which indicated Candida albicans shows some resistance character towards drugs while the herbal extracts of Lawsonia inermis, Withania somnifer, Curcuma longa, Cymbopogon citrates and Zingiber officinale gives the best inhibitory effect and they have the potential to control growth of Candida albicans.
\end{abstract}

\section{Introduction}

Presently, oral infection one of the most prevalent type of disease is a growing health problem around the world. Oral Carcinoma (SCC), a multistage process from normal to dysplastic lesions. A premalignant or precancerous lesion, a morphologically altered tissue in which cancer is more likely to occur and includes oral leukoplakia, oral erythroplakia, Erythroplakia and possibly oral Sub mucous fibrosis. Oral submucous fibrosis, a potentially malignant disease being predominantly found in people of Asian descent. Fibrosis is the histopathological hallmark of the disease that affects most parts of the oral cavity. The prevalence of the disease is on the rise in South Asia in the recent years. Oral leukoplakias, a white patch on the mucosal surface are histopathologicallydiagnosed as Candida leukoplakia by the presence of hyphae in the superficial epithelium. Candida leukoplakia lesions have significantly increased malignant potential. Candida albicans is the most prevalent fungal species associated with oral leukoplakia and may contribute to malignant transformation of Candida leukoplakia. The term erythroplakia is used for a clinically and histopathologically similar process that occurs on the oral mucosa. Similar to the definition for leukoplakia, it is a clinical term that refers to a red patch that cannot be defined clinically or pathologically like any other condition. In oral cavity, the oral micro flora may be subsequently replaced by potentially pathogenic microorganisms, such as Candida sp., (from $72 \%$ to $92 \%$ ), Candida carriage was reported to be common in oral cancer patients also, with $C$. albicans being the predominant species. ${ }^{1},{ }^{2}$ Candidal Oral colonization (up to 93\%) and infection (up to 30\%) are frequently noted in oral cancer patient. ${ }^{3}$ The main reason may be the irradiationinduced histological changes which lead to oral mucositis, together with salivary quantitative and qualitative changes, which facilitate candidal growth. Beside that a possible explanation for the higher predisposition of irradiated patients to candidosis is due to reduced phagocytic activity of salivary granulocytes against this micro-organisms. $^{4}$

Candida, an ubiquitous fungi, belongs to the phylum Ascomycota are thin-walled, small (4 to 6 microns) reproduce by budding and are

\footnotetext{
* Corresponding author.

E-mail address: fahadmsamadi@gmail.com (F.M. Samadi).
} 
Table 1

Diameters of the inhibition zones by leaves extracts of methanol.

\begin{tabular}{|c|c|c|c|c|c|c|}
\hline Leaf extracts & Volume of extract (ml) & $100 \mathrm{mg} / \mathrm{ml}$ & $50 \mathrm{mg} / \mathrm{ml}$ & $25 \mathrm{mg} / \mathrm{ml}$ & $10 \mathrm{mg} / \mathrm{ml}$ & $5 \mathrm{mg} / \mathrm{ml}$ \\
\hline Lawsonia inermis & 0.2 & $27 \pm 0.13$ & $24 \pm 0.26$ & $21 \pm 0.17$ & $18 \pm 0.04$ & $17 \pm 0.22$ \\
\hline Withania somnifera & 0.2 & $24 \pm 0.11$ & $22 \pm 0.08$ & $20 \pm 0.22$ & $18 \pm 0.34$ & $16 \pm 0.16$ \\
\hline Zingiber officinale & 0.2 & $22 \pm 0.25$ & $21 \pm 0.15$ & $18 \pm 0.09$ & $15 \pm 0.43$ & $13 \pm 0.12$ \\
\hline Curcuma longa & 0.2 & $30 \pm 0.57$ & $27 \pm 0.21$ & $26 \pm 0.42$ & $23 \pm 0.13$ & $22 \pm 0.06$ \\
\hline Cymbopogon citrates & 0.2 & $19 \pm 0.49$ & $18 \pm 0.39$ & $13 \pm 0.19$ & $12 \pm 0.28$ & $11 \pm 0.21$ \\
\hline Tamarindus indica & 0.2 & $14 \pm 0.09$ & $14 \pm 0.20$ & $13 \pm 0.28$ & $11 \pm 0.24$ & $10 \pm 0.36$ \\
\hline Limonia acidissima & 0.2 & $10 \pm 0.16$ & $09 \pm 0.11$ & $08 \pm 0.24$ & $08 \pm 0.16$ & $07 \pm 0.04$ \\
\hline Psidium guajana & 0.2 & $15 \pm 0.20$ & $13 \pm 0.18$ & $12 \pm 0.02$ & $12 \pm 0.17$ & $10 \pm 0.17$ \\
\hline Annona reticulata & 0.2 & $12 \pm 0.19$ & $11 \pm 0.23$ & $10 \pm 0.34$ & $09 \pm 0.12$ & $08 \pm 0.17$ \\
\hline Swertia chirata & 0.2 & $16 \pm 0.28$ & $15 \pm 0.18$ & $1 \pm 0.14$ & $11 \pm 0.29$ & $10 \pm 0.43$ \\
\hline Euphorbia hirta & 0.2 & $30 \pm 0.32$ & $28 \pm 0.06$ & $27 \pm 0.20$ & $26 \pm 0.23$ & $24 \pm 0.15$ \\
\hline Pogostemon parviflorus & 0.2 & $26 \pm 0.41$ & $22 \pm 0.16$ & $19 \pm 0.14$ & $17 \pm 0.41$ & $15 \pm 0.06$ \\
\hline Adenocalymma alliacum & 0.2 & $25 \pm 0.22$ & $23 \pm 0.03$ & $22 \pm 0.31$ & $17 \pm 0.02$ & $14 \pm 0.23$ \\
\hline Echinophora platybola & 0.2 & $31 \pm 0.17$ & $25 \pm 0.12$ & $23 \pm 0.22$ & $21 \pm 0.19$ & $20 \pm 0.20$ \\
\hline Cuminum cyminum & 0.2 & $18 \pm 0.19$ & $15 \pm 0.23$ & $13 \pm 0.34$ & $11 \pm 0.12$ & $07 \pm 0.17$ \\
\hline
\end{tabular}

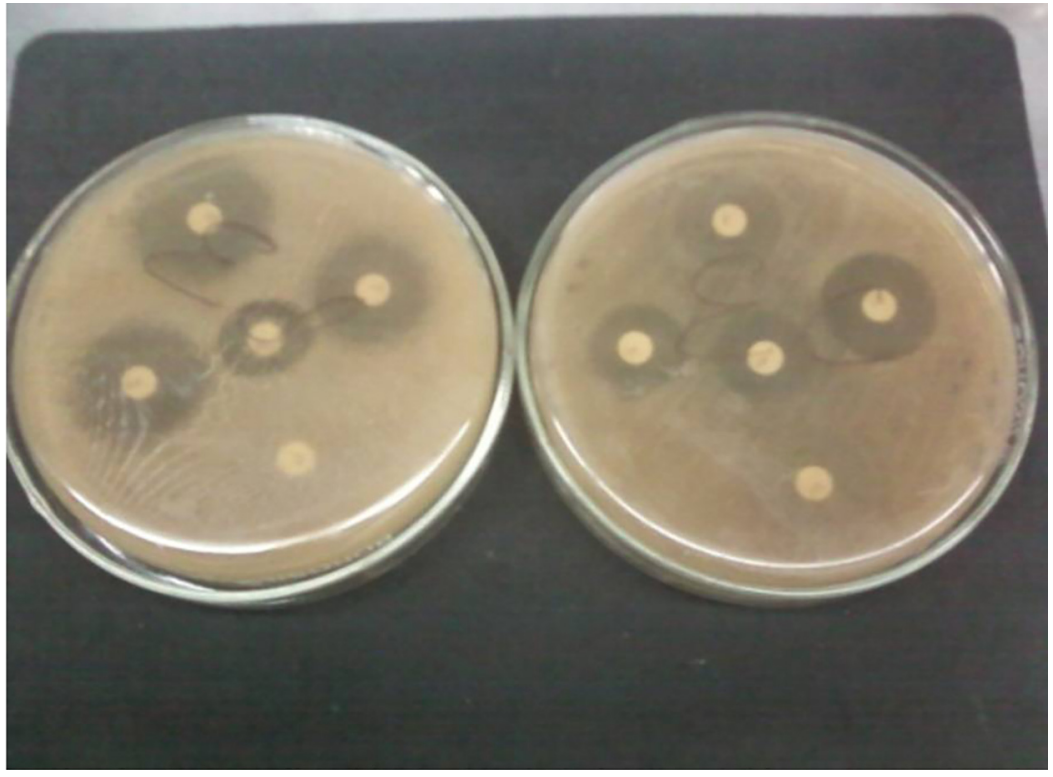

Fig. 1. $\mathrm{xxx}$.

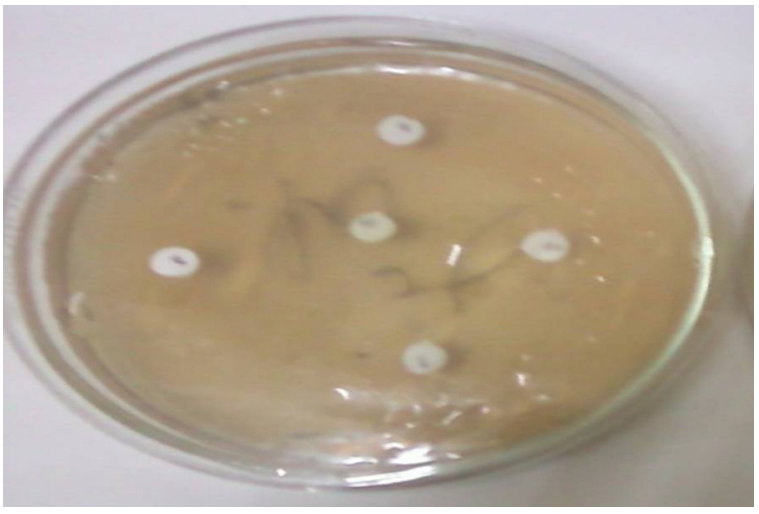

Fig. 2. Close-up of inhibition Zones.

one of the most common causes of opportunistic mycoses worldwide. They grow rapidly and mature in 3 days. The colonies of Candida are cream yellowish in color. The texture of the colony may be pasty, smooth, dry, wrinkled and dull, depending on the species. They can be recovered from environmental, human and other mammalian sources. The prevalence of diseases caused by Candida species have been found to increase in recent years, mainly in pregnant, diabetic, elderly or immune-compromised individuals, or those who are receiving antibiotic or corticosteroid treatment as appear to be predisposing factors for Candida infection. ${ }^{5}$ Clinically important Candida species in humans includes Candida albicans, Candida glabrata, Candida tropicalis, Candida parapsilosis and Candida dubliniens is among which C. albicansis the most prevalent pathogenic species which is responsible for the majority of oral and systemic infections. ${ }^{6}$ More recently, it has been suggested that Candida albicans species may be the causative agents of oral precancer. ${ }^{4}$ There have been some reports in the literature linking the presence of Candida albicans with the clinical condition of linear gingival erythema that is occasionally seen in HIV-infected patients. ${ }^{7}$ Mycological studies have shown that C. albicans represents over $80 \%$ of isolates from all forms of human candidosis. ${ }^{8}$ However, in the past ten years, a fivefold increase in candidaemia has been reported, ${ }^{9}$ and the current incidence of candidaemia per 1000 admissions in Europe ranges from 0.17 to 20 depending on the country and patient group studied. ${ }^{10}$ There are no drugs which can effect extremely to treat oral infections caused by Candida. There is a general call for new emerging drugs that are highly effective towards oral infections which possess low toxicity, and have a minor environment impact. Novel natural products offer opportunities for innovation in drug discovery. A considerable number of antifungal agents currently used in the clinic are of natural origin. All the drugs from the plants are substances with the particular therapeutic actions 
Table 2

Calculated MIC part 1.

\begin{tabular}{|c|c|c|c|c|c|c|}
\hline Leaf extracts & Volume of extract (ml) & $100 \mathrm{mg} / \mathrm{ml}$ & $50 \mathrm{mg} / \mathrm{ml}$ & $25 \mathrm{mg} / \mathrm{ml}$ & $10 \mathrm{mg} / \mathrm{ml}$ & $5 \mathrm{mg} / \mathrm{ml}$ \\
\hline Lawsonia inermis & 0.2 & $22 \pm 0.13$ & $22 \pm 0.26$ & $18 \pm 0.17$ & $16 \pm 0.04$ & $10 \pm 0.22$ \\
\hline Withania somnifera & 0.2 & $28 \pm 0.11$ & $25 \pm 0.08$ & $22 \pm 0.22$ & $19 \pm 0.34$ & $17 \pm 0.16$ \\
\hline Zingiber officinale & 0.2 & $24 \pm 0.25$ & $22 \pm 0.15$ & $20 \pm 0.09$ & $19 \pm 0.43$ & $16 \pm 0.12$ \\
\hline Curcuma longa & 0.2 & $21 \pm 0.57$ & $19 \pm 0.21$ & $18 \pm 0.42$ & $17 \pm 0.13$ & $15 \pm 0.06$ \\
\hline Cymbopogon citrates & 0.2 & $17 \pm 0.49$ & $15 \pm 0.39$ & $12 \pm 0.19$ & $08 \pm 0.28$ & $06 \pm 0.21$ \\
\hline Tamarindus indica & 0.2 & $13 \pm 0.09$ & $12 \pm 0.20$ & $09 \pm 0.18$ & $09 \pm 0.24$ & $07 \pm 0.36$ \\
\hline Limonia acidissima & 0.2 & $09 \pm 0.26$ & $08 \pm 0.11$ & $07 \pm 0.31$ & $05 \pm 0.06$ & $05 \pm 0.04$ \\
\hline Psidium guajana & 0.2 & $13 \pm 0.20$ & $12 \pm 0.18$ & $11 \pm 0.02$ & $10 \pm 0.17$ & $09 \pm 0.17$ \\
\hline Annona reticulata & 0.2 & $12 \pm 0.19$ & $11 \pm 0.23$ & $11 \pm 0.34$ & $10 \pm 0.12$ & $07 \pm 0.17$ \\
\hline Swertia chirata & 0.2 & $19 \pm 0.28$ & $18 \pm 0.18$ & $18 \pm 0.14$ & $17 \pm 0.29$ & $16 \pm 0.43$ \\
\hline Euphorbia hirta & 0.2 & $26 \pm 0.02$ & $23 \pm 0.25$ & $19 \pm 0.11$ & $17 \pm 0.21$ & $14 \pm 0.11$ \\
\hline Pogostemon parviflorus & 0.2 & $30 \pm 0.17$ & $28 \pm 0.22$ & $26 \pm 0.04$ & $21 \pm 0.28$ & $19 \pm 0.15$ \\
\hline Adenocalymma alliacum & 0.2 & $20 \pm 0.06$ & $17 \pm 0.19$ & $15 \pm 0.09$ & $13 \pm 0.12$ & $11 \pm 0.23$ \\
\hline Echinophora platybola & 0.2 & $32 \pm 0.23$ & $29 \pm 0.33$ & $25 \pm 0.10$ & $23 \pm 0.18$ & $22 \pm 0.14$ \\
\hline Cuminum cyminum & 0.2 & $11 \pm 0.21$ & $11 \pm 0.16$ & $09 \pm 0.25$ & $08 \pm 0.07$ & $05 \pm 0.03$ \\
\hline
\end{tabular}

Table 3

Calculated MIC part 2.

\begin{tabular}{llll}
\hline Drug / Control & $\begin{array}{l}\text { Concentration Of } \\
\text { drug( } \mu \mathrm{g} / \mathrm{disc})\end{array}$ & $\begin{array}{l}\text { Zone of } \\
\text { inhibition } \\
(\mathrm{mm})\end{array}$ & $\begin{array}{l}\text { Resistance/ } \\
\text { Sensitive }\end{array}$ \\
\hline Fluconazole & $10 \mu \mathrm{g} / \mathrm{disc}$ & 09 & $\mathrm{R}$ \\
Cotrimoazol & $25 \mu \mathrm{g} / \mathrm{disc}$ & 18 & $\mathrm{~S}$ \\
Erythromycin & $10 \mu \mathrm{g} / \mathrm{disc}$ & 10 & $\mathrm{R}$ \\
$\begin{array}{l}\text { Minocycline } \\
\text { Negative Control- } \\
\text { Methanol }\end{array}$ & $5 \mu \mathrm{g} / \mathrm{disc}$ & 13 & $\mathrm{~S}$ \\
$\begin{array}{c}\text { Negative Control- } \\
\text { Ethanol }\end{array}$ & $0.2 \mathrm{ml}$ & - & $\mathrm{R}$ \\
\hline
\end{tabular}

extracted from the plants. In fact, natural products play a major role in controlling infections and treatment by inhibiting the growth of responsible pathogen. For instance, over half of drugs approved internationally between the 1940s and 2006 were natural products or their derivatives. ${ }^{11}$ Among them, plants have been the chief source of natural compounds used for medicine.

\subsection{Antifungal activity of herbal plants extract against Candida albicans}

The prospective study was done to explore the plants having antifungal activity towards Candida albicans which can further be used in treatment of oral candidal infection and in oral mucosal lesions. To investigate the bioactivity of plants against Candida albicans, fifteen plants were randomly selected. Pathogen samples were collected from the patients by the method already described in. Fresh and mature leaves of plants Lawsonia inermis, Withania somnifera, Swertia chirata, Curcuma longa, Cymbopogon citrates, Tamarindus indica, Limonia acidissima, Psidium guajana, Annona reticulate Cuminum cyminum, Euphorbia hirta, Pogostemon parviflorus, Adenocalymma alliacum, Echinophora platybola and stem of Zingiber officinale were collected from Department of Botany, University of Lucknow old campus, Lucknow and National Botanical Research Institute, Lucknow during March-May 2015. Samples were collected in sterile plastic bag and brought to Mycology Laboratory of Botany Department, University of Lucknow, Lucknow, India.

\section{Method and material}

\subsection{Chemicals}

Sabarouds Dextrose Agar (SDA), antifungal discs like Erythromycin (10 $\mu \mathrm{g} / \mathrm{disc}), \quad$ Minocycline $(5 \mu \mathrm{g} /$ disc $), \quad$ Clotrimazole $(25 \mu \mathrm{g} / \mathrm{disc})$, Fluconazole $(10 \mu \mathrm{g} / \mathrm{disc})$ were purchased from Himedia Pvt. Ltd.,
Mumbai, India. Other chemicals and reagents used for the study were of analytical grade.

\subsection{Microorganisms}

Micro-organism namely Candida albicans was collected from the Department of Oral Pathology and Microbiology Laboratory, isolated from the oral cavity of patients by sterile cotton swabs.

\subsection{Extract preparation}

The leaves of plants were washed thoroughly with distilled water and dried at room temperature. Dried leaves were uniformly grounded using a mechanical grinder to yield fine powder. Ten grams of the powder was mixed with $100 \mathrm{ml}$ of methanol in conical flask and kept in shaking incubator at $100 \mathrm{rpm}$ for $24 \mathrm{~h}$. The mixture was filtered using Whatman filter paper no 1. Extract was dried and stored in an airtight container at $4{ }^{\circ} \mathrm{C}$ until further use.

\subsection{Preparation of extracts in methanol solution and isolated fractions for antifungal activity test}

Exactly $0.2 \mathrm{~g}$ of crude methanol extract was dissolved in $2 \mathrm{ml} \mathrm{me-}$ thanol to get $100 \mathrm{mg} / \mathrm{ml}$ concentration. This was then serially diluted to obtain $50 \mathrm{mg} / \mathrm{ml}, 25 \mathrm{mg} / \mathrm{ml}, 10 \mathrm{mg} / \mathrm{ml}$ and $5 \mathrm{mg} / \mathrm{ml}$ concentrations. This procedure was repeated for methanol extracts using methanol as a solvent for dilution. Similar dilution procedure was applied for the fractions corresponding to their yield. All of the fractions were prepared in two to three fold dilutions. It should be clear that for those samples in which organic solvents were used for dilution, when antimicrobial test was done filter paper disks after impregnated in the stock solution was left to dry in flat glass (to let the solvent evaporated) and then it was sprayed with sterile distilled water.

\subsection{Preparation of extracts in ethanol solution and isolated fractions for antifungal activity test}

Exactly $0.2 \mathrm{~g}$ of crude ethanol extract was dissolved in $2 \mathrm{ml}$ ethanol to get $100 \mathrm{mg} / \mathrm{ml}$ concentration. This was then serially diluted to obtain $50 \mathrm{mg} / \mathrm{ml}, 25 \mathrm{mg} / \mathrm{ml}, 10 \mathrm{mg} / \mathrm{ml}$ and $5 \mathrm{mg} / \mathrm{ml}$ concentrations. This procedure was repeated for methanol extracts using ethanol as a solvent for dilution. Similar dilution procedure was applied for the fractions corresponding to their yield. All of the fractions were prepared in two to three fold dilutions. It should be clear that for those samples in which organic solvents were used for dilution, when antimicrobial test was done filter paper disks after impregnated in the stock solution was left to dry in flat glass (to let the solvent evaporated) and then it was 
sprayed with sterile distilled water.

\subsection{Controls used in the study}

Erythromycin (10 $\mu \mathrm{g} / \mathrm{disc})$, Minocycline (5 $\mu \mathrm{g} / \mathrm{disc})$, Clotrimazole ( $25 \mu \mathrm{g} / \mathrm{disc})$, Fluconazole $(10 \mu \mathrm{g} / \mathrm{disc})$ were used as a reference or positive control for $C$. albicans methanol and ethanol solutions were used as negative controls for the study.

\subsection{Antimicrobial activity assay}

Agar disc diffusion method was performed for antifungal screening and broth dilution method for determination of minimum inhibitory concentration was applied as described elsewhere with little modification. Disc diffusion method was employed in the preliminary antimicrobial screening of both the crude organic extracts and bioassay guided isolated compounds. Test strains suspension of 0.5 McFarland was prepared from fresh cultures using normal saline. The plates were aseptically streaked with the test microorganism using a sterile swab and allowed to dry for few minutes. Sterile $6 \mathrm{~mm}$ diameter filter paper discs were impregnated with stock solutions (at concentrations 5, 10, 25 , 50 , to $100 \mathrm{mg} / \mathrm{ml}$ ). Using sterile forceps the discs were placed aseptically on the inoculated agar plates. The plates were then incubated for $24 \mathrm{~h}$ at $350 \mathrm{C}$. The experiments were carried out in triplicates. Presence of a clear circular zone around the sample impregnated disc was used as an indicator of activity. The results (mean values, $\mathrm{n}=3$ ) were recorded by measuring zones diameter in millimeters with the help of calipers. Disc Impregnated with the solvents used methanol and ethanol were included as negative controls. For comparative purposes standard drug clotrimazole $(25 \mu \mathrm{g} / \mathrm{disc})$ for antifungal was included as positive controls in the assays respectively. ${ }^{12}, 13$

\subsection{Minimum inhibitory concentration (MIC)}

The extracts, which showed superior antifungal activity in the agar disc diffusion method, were subjected to the MIC assay. The minimum inhibitory concentration (MIC) of the extracts was determined for the test organisms in triplicates. To a $0.5 \mathrm{ml}$ of varying concentrations of the extracts $(20.0,15.0,10.0,5.0$ and $1.0 \mathrm{mg} / \mathrm{ml}), 2 \mathrm{ml}$ of nutrient broth was added (so the extracts were dilute by a factor of 5 ). Therefore the final concentrations were $4,3,2,1,0.2$, and $0 \mathrm{mg} / \mathrm{ml}$ as a control), and then a loopful of the test organism previously adjusted to 0.5 McFarland turbidity standard was introduced to the tubes. The procedure was repeated on the test organisms using the standard antibiotic (clotrimazole $40 \mu \mathrm{g} / \mathrm{disc}$ ). A tube containing nutrient broth only was seeded with the test organisms as described above to serve as control. Tubes containing cultures were then incubated at $37^{\circ} \mathrm{C}$ for $24 \mathrm{~h}$ period. After incubation the tubes were then examined for candidal growth by observing the turbidity present in the tubes.

\subsection{Data collection}

The antifungal activity of the selected herbs against fungus Candida albicans were obtained by measuring the diameters of the inhibition zones and compared them with that of the positive control drug Fluconazole, erythromycin, minocyline and clotrimazole and negative control methanol and ethanol. Antifungal activity was expressed as the mean zone of inhibition diameters $(\mathrm{mm})$ produced by the herbs extracts.

\section{Results}

Results showed that Candida albicans shows most sensitivity towards the standard antibiotic cotrimoazol but very less towards other drugs like Fluconazole, minocycline, erythromycin respectively which indicated Candida albicans shows some resistance character towards drugs. However, the diameters of the inhibition zones by leaves extracts of methanol and ethanol solvents of selected herbs (Lawsonia inermis, Withania somnifera, Curcuma longa, Cymbopogon citrates, Limonia acidissima, Tamarindus indica, Swertia chirata, Psidium guajana, Annona reticulate, stem of Zingiber officinale, Euphorbia hirta, Pogostemon parviflorus, Adenocalymma alliacum, Echinophora platybola and Cuminum cyminum) against the pathogen Candida albicans are different at different concentrations (Table 1, Fig. 1) among which the herbal extracts of Lawsonia inermis, Withania somnifera, Curcuma longa, Cymbopogon citrates and Zingiber officinale gives the best inhibitory effect and they have the potential to control growth of Candida albicans as they have diameter zone of inhibition above $12 \mathrm{~mm}$ at MIC $25 \mathrm{mg} / \mathrm{ml}, 25 \mathrm{mg} / \mathrm{ml}$, $10 \mathrm{mg} / \mathrm{ml}, 50 \mathrm{mg} / \mathrm{ml}$ and $10 \mathrm{mg} / \mathrm{ml}$ respectively (Fig. 2).

In methanolic extract the best antifungal activity was given by Lawsonia inermis, Withania somnifera, Zingiber officinale, Curcuma longa, Euphorbia hirta, Pogostemon parviflorus, Adenocalymma alliacum and Echinophora platybola. The calculated MIC $(\mathrm{mg} / \mathrm{ml})$ was 2.8, 3.2, 5.0, 2.10, 1.5, 4.30 and 3.15 (Tables 2 and 3).

In ethanolic extract the best antifungal activity was given by Withania somnifera, Zingiber officinale, Curcuma longa, Swertia chirata, Euphorbia hirta, Pogostemon parviflorus, Adenocalymma alliacum and Echinophora platybola. The calculated MIC $(\mathrm{mg} / \mathrm{ml})$ was $3.10,2.81,4.25,2.75,4.25,3.85$ and 2.30 .

The herbal extracts of Withania somnifera, Curcuma longa, Euphorbia hirta, Echinophora platybola, Zingiber officinale, Lawsonia inermis, Adenocalymma alliacum, Pogostemon parviflorus and Swertia chirata gives the best inhibitory effect at MIC $5 \mathrm{mg} / \mathrm{ml}$ and they have the potential to control growth of Candida albicans as they have diameter zone of inhibition above $12 \mathrm{~mm}$ at MIC. Leaves extract of Withania somnifera, Curcuma longa, Euphorbia hirta, Echinophora platybola, Zingiber officinale shows the inhibitory effect at MIC $5 \mathrm{mg}$ / $\mathrm{ml}$ in all the methanol and ethanol while Lawsonia inermis and Adenocalymma alliacum shows the inhibitory effect only in methanol, Pogostemon parviflorus in methanol and ethanol and Swertia chirata, shows inhibitory effect at MIC $5 \mathrm{mg} / \mathrm{ml}$ only in ethanolic extract solution. Leaves extract of Limonia acidissima and Annona reticulate gives negative effects at all the conc. against the treated pathogen.

\subsection{Statistical analysis}

One way Analysis Of Variance (ANOVA) was used to determine the means, the standard deviations and the p-value. Student $t$-test was used to determine significance of the difference of the antifungal activities of the extracts. Results obtained in this study were expressed as mean inhibition zone $(\mathrm{mm}) \pm$ S.D of three replicates. The mean and the S.D of each herbal extracts were used to compute the calculated t-value. Differences between the critical t-value and calculated t-values of the diameter of the inhibition zones of the herbal extracts on Candida albicans were computed. Among all the fifteen herbal species five (Lawsonia inermis, Withania somnifera, Curcuma longa, and Zingiber officinale gives) gives the alternate hypothesis because the calculated $\mathrm{t}$ value was more than the critical t-value at $p 0.05$ hence there is a significant biological activity displayed by the compounds of these five herbs.

\section{Discussion}

Presently rise in Candida infections could also be due to a reflection of inherently higher level of antifungal drug resistance in some Candida species. The exact mechanism of biofilm resistance to antifungals remains unclear, but it is probably multifactorial. The extracellular polysaccharide of the biofilm could serve as an inhibitor to diffusion of an antimicrobial agent or ionically bind the drug as it diffuses through the biofilm, thereby effectively reducing its bioavailability. ${ }^{14}$ The infections caused by opportunistic fungi like Candida albicans are included under new spectrum of fungal pathogens. There is an increasing 
awareness amongst clinicians and microbiologists pertaining to importance of infection caused by opportunistic fungi (Candida albicans). Novel natural products offer opportunities for innovation in drug discovery. A considerable number of antitumor agents currently used in the clinic are of natural origin. In fact, natural products play a major role in controlling infections and treatment by inhibiting the growth of responsible pathogen. For instance, over half of drugs approved internationally between the $1940 \mathrm{~s}$ and 2006 were natural products or their derivatives. ${ }^{11}$ Among them, plants have been the chief source of natural compounds used for medicine. The use of herbs and medicinal plant compounds to treat infections is an old age practice throughout the world, especially in developing countries, where is there is dependence on traditional medicine for a variety of diseases. All the drugs from the plants are substances with the particular therapeutic actions extracted from the plants. The increased prevalence of antibiotic resistant fungal organisms is due to the extensive use of antibiotics may render the current antimicrobial agents insufficient to control some bacterial diseases and hence research for identifying novel substances that are active against human pathogens is an urgent need. The antimicrobial compounds produced by plants are active against plant and human pathogenic microorganisms. There is a general call for new emerging drugs that are highly effective towards infections, possess low toxicity, and have a minor environment impact. Many pharmacological investigations are also in race to identify new herbal drugs for the treatment of human infectious diseases.

\section{Conclusion}

The findings of this suggest that these herbs (Withania somnifera, Curcuma longa, Euphorbia hirta, Echinophora platybola, Zingiber officinale, Lawsonia inermis, Adenocalymma alliacum, Pogostemon parviflorus and Swertia chirata) in specific solution can be best used in treatment of oral infection by Candida albicans as they are natural, effective at MIC $5 \mathrm{mg} / \mathrm{ml}$ without any toxic effects. These herbs can also be used in oral gels, tooth pastes, oral ointments to vanish candidal infections or to inhibit its colonial growth at an early stage because they can proliferate in oral cavity, penetrate their hyphae in oral epithelium which may proves them to be very harmful. The effective herbs can be used to treat infection at very low costs by using the effective herbal components in tooth pastes, oral gels, ointments etc. as by use of these products will totally vanishes the fungal colony from oral cavity without resulting in any side effects or toxicity like drugs. As use of chemical antimicrobial agents also enhances the resistivity character of microbes or fungus but these herbal products will not show any effect on enhancing resistivity character of this pathogenic fungus this might also be the best of its use.

\section{References}

1. Leung WK, Dassanayake RS, Yau JYY, Jin LJ, Yam WC, Samaranayake. LP: Oral colonization, phenotypic, and genotypic profiles of Candida species in irradiated, dentate, xerostomic, nasopharyngeal carcinoma survivors. J Clin Microbiol. 2000;38:2219-2226

2. Al-Abeid HM, Abu-Elteen KH, Elkarmi AZ, Hamad MA. Isolation and haracterization of Candida Spp. In: Jordanian cancer patients: prevalence, pthogenic determinants, and antifungal sensitivity. Jpn J Infect Dis. 2004;57:279-284.

3. Ramirez-Amador V, Silverman Jr S, Mayer P, Tyler Mand Quivey J. Candidal colonization and Oral candidiasis in patients undergoing Oral and pharyngeal radiation therapy. Oral Surg Oral Med Oral Pathol Radiol Endod. 1997;84:149-153.

4. Sitheeque MA, Samaranayake LP. Chronic hyperplastic candidosis/Candidiasis (candidal leukoplakia). Crit Rev Oral Biol Med. 2003;14:253-267.

5. Lockhart SR, Daniels KJ, Zhao R, Wessels D, Soll DR. Cell biology of mating in Candida albicans. Eukaryot Cell. 2003;2:49-61.

6. Thompson GR, Patel PK, Kirkpatrick WR, et al. Oropharyngeal candidiasis in the era of antiretroviral therapy. Oral Surg Oral Med Oral Pathol Oral Radiol Endod. 2010;109:488-492.

7. Velegraki A, Nicolatou O, Theodoridou M, Mostrou G, Legakis NJ. Paediatric IDSrelated linear gingival erythema: a form of erythematous candidiasis? J Oral Pathol Med. 1999;28:178-182.

8. Pfaller MA, Diekema DJ. Epidemiology of invasive candidiases: a persistent public health problem. Clin Microbiol Rev. 2007;20:133-163.

9. Bassetti M, Ansaldi F, Nicolini L, et al. Incidence of candidaemia and relationship with fluconazole use in an intensive care unit. $J$ Antimicrob Chemother. 2009;64:625-629.

10. Lass-Florl C. The changing face of epidemiology of invasive fungal disease in Europe. Mycoses. 2009;52:197-205

11. Efferth T, Li PCH, Konkimalla VSB, Kaina B. From traditional Chinese medicine to rational cancer therapy. Trends Mol Med. 2007;13:353-361.

12. Shahverdi A, Iranshahi M, Mirjani R, Jamalifar H, Amin G, Shafiee A. Bioassayguided isolation and identification of an antibacterial compound from Ferula persica var. Persica Roots DARU. 2005;13:17-19.

13. Seyydnejad MS, Niknejad M, Darabpoor I, Motamedi H. Antibacterial activity of hydroalcoholic extract of callistemon citrinus and Albizia lebbeck. Am J Appl Sci. 2010;7:13-16.

14. Al-Fattani MA, Douglas LJ. Penetration of Candida biofilms by antifungal agents. Antimicrob Agents Chemother. 2004;48:3291-3297. 